\title{
Antenatal ultrasonographic diagnosis of congenital high airway obstruction syndrome - a chaotic state: a case report
}

\author{
Bindushree Kadakola ${ }^{1}$, Shruthi P.S. ${ }^{2}$, Suraj Jain ${ }^{2}$
}

\author{
${ }^{1}$ Department of Radiodiagnosis, Shridevi Institute of Medical Sciences and Research Hospital (SIMSRH), Tumkur, \\ Karnataka, India \\ ${ }^{2}$ Department of Pathology, Shridevi Institute of Medical Sciences and Research Hospital (SIMSRH), Tumkur, \\ Karnataka, India
}

Received: 21 August 2015

Revised: 04 September 2015

Accepted: 09 September 2015

\section{*Correspondence: \\ Dr. Bindushree Kadakola, \\ E-mail: bkadakola.mp@gmail.com}

Copyright: $\odot$ the author(s), publisher and licensee Medip Academy. This is an open-access article distributed under the terms of the Creative Commons Attribution Non-Commercial License, which permits unrestricted non-commercial use, distribution, and reproduction in any medium, provided the original work is properly cited.

\begin{abstract}
Congenital high airway obstruction syndrome is a fatal condition of multifactorial inheritance. It can be partial or complete. Most common cause of this is laryngeal atresia incompatible with life. Prenatal diagnosis becomes important due to recent management options. Here we report a case of congenital high airway obstruction, diagnosed on antenatal ultrasonography at 26 weeks of gestation. Parents decided to terminate the pregnancy and observations were confirmed on autopsy.
\end{abstract}

Keywords: Inheritance, Syndrome, Prenatal, Ultrasonography

\section{INTRODUCTION}

Congenital high airway obstruction syndrome (CHAOS) is defined as complete or partial obstruction of the fetal upper airways. This clinical condition was brought into notice firstly by Hedrick in the late 1900 s. ${ }^{1}$ It is a Fatal condition presenting with hyperinflated, enlarged and highly echogenic lungs, an inverted or flattened diaphragm, a dilated tracheobronchial tree and ascites. It occurs as a result of congenital obstruction of the fetal airway secondary to laryngeal atresia, tracheal atresia, or a laryngeal cyst. ${ }^{1} \quad$ The disease is generally incompatible with life. However a recent advance in the antenatal management like laryngeal web dissection in partial obstructive cases has led to better outcome of the pregnancy. Ultrasonographic (USG) diagnosis of this entity would help in deciding the continuation or termination in severe cases.

\section{CASE REPORT}

A 27-year-old multiparous (Gravida 2) woman married to first degree consanguinity came for antenatal scan at 28 weeks gestation for fetal well-being examination. She had missed her regular 18-22 weeks scan for anomalies. Family history was unremarkable. Her previous pregnancy had been uneventful with a female healthy baby. Ultrasonography showed gross ascites with liver floating in the midline. Bilateral lungs were hyperechoic, over distended compressing the cardia in midline. The Larynx, trachea, bronchus were dilated with pruning seen distally (Figure $1 \mathrm{~A}$ and $\mathrm{B}, \mathrm{C}$ ). No cystic lesions where seen in the lungs. Normal amniotic fluid was seen. No extrinsic cause of obstruction like lymphatic cysts was seen. No luminal cause or site of obstruction could be demonstrated on ultrasonography. Placenta was abnormally echogenic and bulky .Rest of the structures appeared normal. Cardia was normal except for the compression by the distended lungs. 
Differential diagnosis of Congenital cystic airway disease type III (CCAM) and congenital high airway obstruction (CHAOS) was given. The parents decided for the termination of pregnancy after being explained about the risk of continuation of pregnancy. Pregnancy was terminated by induction with the dead fetus weighing approximately $300 \mathrm{gm}$. Placenta looked grossly bulky with normal three vessel cord.

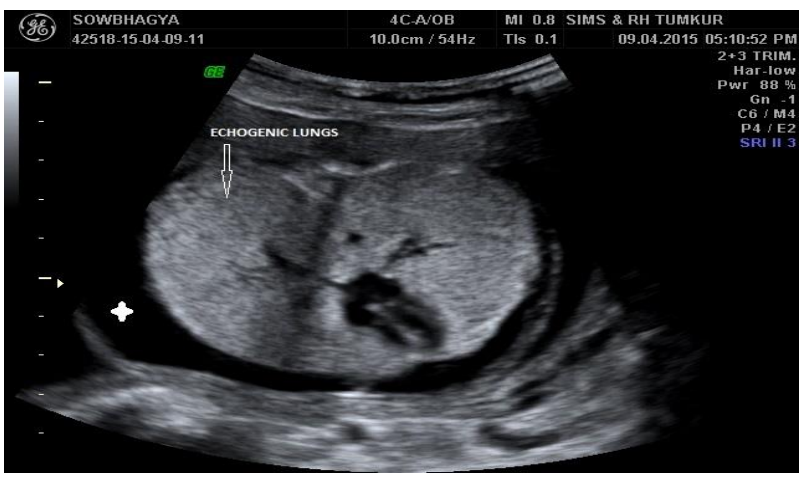

Figure 1: Antenatal ultrasonography

Figure 1A: Bilateral over distended echogenic lungs with cardia compressed in midline. The cross symbol represents gross ascites.

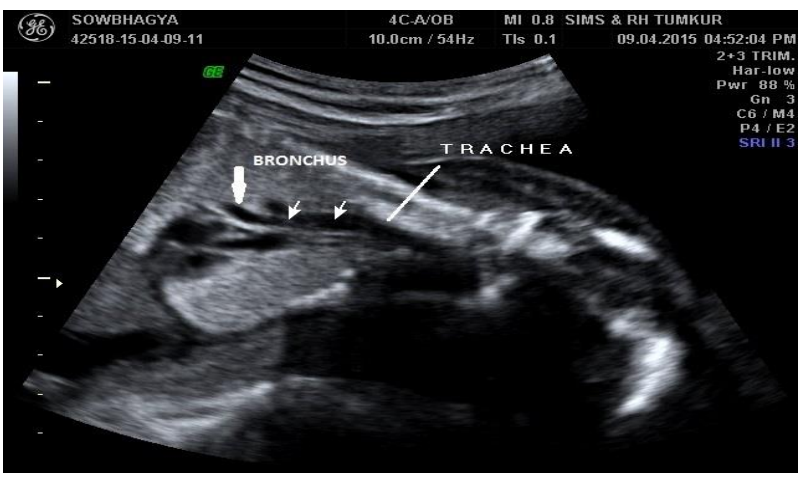

Figure 1B: Linear line represents dilated trachea and arrows represents dilated bronchus.

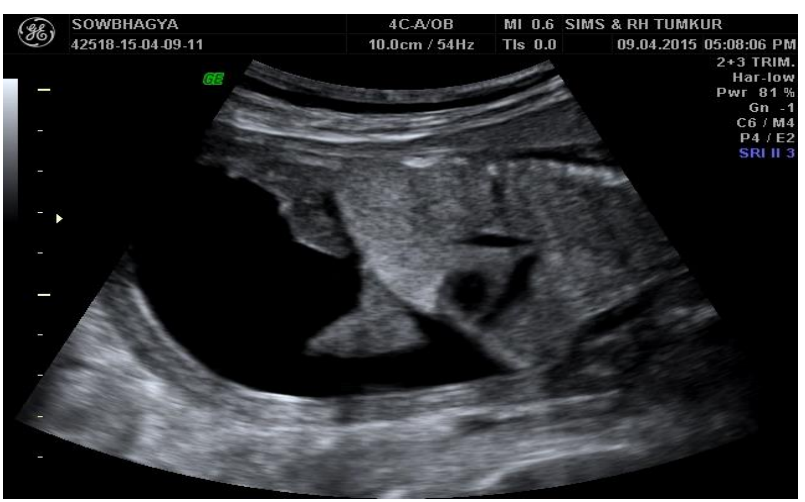

Figure 1C: Inverted diaphragm with ascites.

\section{Autopsy findings}

With parents consent fetus was taken for the autopsy.

\section{Macroscopic findings}

Revealed distended echogenic lungs weighing each more than 8 grams was seen herniating outside the abdomen because of increased pressure while expulsion of the fetus. Right lung had three lobes and left two. Bronchus, trachea and larynx were dilated. Diaphragm was inverted and seen closely approximating the under surface of lungs. Larynx showed dilatation up to the supraglottic part with sudden narrowing above the supraglottic region thus suggesting atresia.
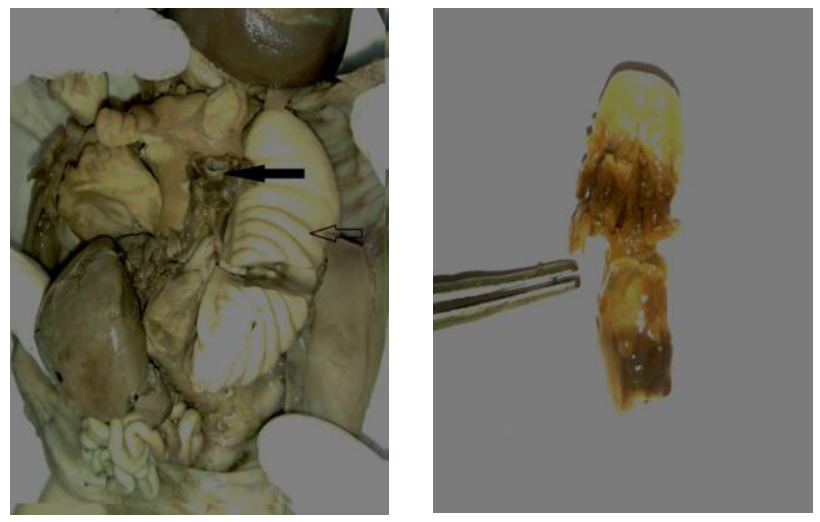

FIGURE 2: Autopsy specimen (A) Empty arrow shows over distended lungs with external impressions by the ribs. Solid arrow shows dilated trachea (B)

Forcep tip pointing at the abrupt narrowed supra glottis area suggesting atresia.

\section{DISCUSSION}

Tracheal atresia is a very rare congenital malformation which takes place by deficient recanalization of the upper airways around the 10th week of gestation resulting in a clinical spectrum defined as congenital high airway obstruction syndrome (CHAOS). ${ }^{1}$ In a healthy fetus, the fluid secreted by fetal lung is absorbed through the tracheobronchial tree. However, in case of any obstruction in the tracheobronchial tree, this fluid cannot be cleared. The accumulation of the fetal lung fluid results in gradual increase of intratracheal pressure leading to enlargement of the lungs. It is the beginning of a chain reaction: the enlarged lungs cause compression of the heart and great veins. Due to the compression, the heart replaces centrally and becomes small and dysfunctional. Decreased venous return and dysfunctional cardiovascular system end in ascites and hydrops. The diaphragm flattens or inverts according to the severity of the process. $^{2}$

Three possible presentations include (a) complete laryngeal atresia without an oesophageal fistula, (b) complete laryngeal atresia with a trachea-oesophageal 
fistula, and (c) near-complete high upper airway obstruction. ${ }^{3}$

CHAOS is most often misdiagnosed as bilateral congenital cystic adenomatoid malformation (CCAM). ${ }^{1}$ CCAM (especially type III) and upper airway obstruction secondary to intrinsic causes such as tracheal or laryngeal atresia or stenosis and tracheal webs similarly have bilateral uniform hyperechogenic appearance of the fetal lungs on sonographic examination. ${ }^{4}$ In order to make a differentiation between CHAOS and CCAM type III, the obstruction site with distal airway dilatation (present in CHAOS) and the systemic arterial supply (present in CCAM type III) must be clearly seen.

Many aetiologies were proposed including laryngeal or tracheal webs, laryngeal cysts, tracheal atresia, subglottic stenosis or atresia, laryngeal or tracheal agenesis. However, laryngeal atresia appears to be the most frequent cause. Laryngomucocoele is a rare cause of airways obstruction in the neonatal period.,

The sonographic findings of CHAOS include increased in lung size and echogenicity, fluid-filled, dilated trachea, fetal hydrops and polyhydramnios. Prenatal identification of level of atresia is difficult. ${ }^{7}$

Although laryngeal atresia is usually lethal, it has recently become possible to bypass the airway obstruction and establish adequate ventilation by the EXIT procedure (Ex Utero Intrapartum Treatment) or fetoscopic laser decompression, while the fetus is still connected to the placenta. Several successful cases have been reported. 8 "9 Even with the presence of hydrops fetalis, successful fetal intervention by tracheostomy and EXIT procedure were recorded.$^{10,11}$

CHAOS is a rare and fatal cause of congenital airway obstruction if unrecognized during prenatal period. Antenatal sonographic imaging shows typical findings which can lead to a diagnosis. MRI is superior to sonography in demonstrating the level of obstruction and in assisting in the differential diagnosis by excluding extrinsic causes of obstruction can be offered.

\section{ACKNOWLEDGEMENTS}

The authors are thankful to Dr. Sharada, Department of Pathology and Dr. Raman M. Hulinayakar, Department of Medicine.

Funding: No funding sources Conflict of interest: None declared Ethical approval: Not required

\section{REFERENCES}

1. Roybal L, Liechty KW, Hedrick HL, et al. Predicting the severity of congenital high airway obstruction syndrome. Journal of Pediatric Surgery. 2010;45(8):1633-9.

2. Joshi P, Satija L, George RA, et al. "Congenital high airway obstruction syndrome-antenatal diagnosis of a rare case of airway obstruction using multimodality imaging," Medical Journal Armed Forces India. 2012;68(1):78-80.

3. Hartnick CJ, Rutter M, Lang F, Willging JP, Cotton RT. "Congenital high airway obstruction syndrome and airway reconstruction: an evolving paradigm," Archives of Otolaryngology-Head and Neck Surgery. 2002;128(5):567-70.

4. Courtier J, Poder L, Wang ZJ, Westphalen AC, Yeh BM, Coakley FV. "Fetal tracheolaryngeal airway obstruction: prenatal evaluation by sonography and MRI," Pediatric Radiology. 2010;40(11):1800-5.

5. Borko R, Szucs S. Congenital laryngeal cysts. HNO. 2000;48:843.

6. Marien S, Jespers A, Vidts G, et al. Congenital laryngeal cyst: a case report. Acta Otorhinolaryngol Belg. 2003;57:119- 21.

7. Kalache KD, Chaoui R, Tennstedt C, Bollmann R. "Prenatal diagnosis of laryngeal atresia in two cases of congenital high airway obstruction syndrome (CHAOS)," Prenatal Diagnosis. 1997;17:577-81.

8. Kanamori Y, Kitano Y, Hashizume K et al., "A case of laryngeal atresia (congenital high airway obstruction syndrome) with chromosome 5 p deletion syndrome rescued by ex utero intrapartum treatment," Journal of Pediatric Surgery. 2004;39(1):E25-E28.

9. Kohl T, Hering R, Bauriedel G et al., "Fetoscopic and ultrasound-guided decompression of the fetal trachea in a human fetus with Fraser syndrome and congenital high airway obstruction syndrome (CHAOS) from laryngeal atresia," Ultrasound in Obstetrics and Gynecology. 2006;27(1):84-8.

10. Paek BW, Callen PW, Kitterman J et al., "Successful fetal intervention for congenital high airway obstruction syndrome," Fetal Diagnosis and Therapy. 2002;17(5):272-6.

11. Lim FY, Crombleholme TM, Hedrick HL et al., "Congenital high airway obstruction syndrome: natural history and management," Journal of Pediatric Surgery. 2003;38(6):940-45.

Cite this article as: Kadakola B, Shruthi PS, Jain S. Antenatal ultrasonographic diagnosis of congenital high airway obstruction syndrome- a chaotic state: a case report. Int J Reprod Contracept Obstet Gynecol 2015;4:1650-2. 